\title{
Dual polarimetric Radar Vegetation Index for Crop Growth Monitoring Using Sentinel-1 SAR Data
}

\author{
Dipankar Mandal ${ }^{\mathrm{a}, *}$, Vineet Kumar ${ }^{\mathrm{a}, \mathrm{b}}$, Debanshu Ratha ${ }^{\mathrm{a}}$, Subhadip Dey ${ }^{\mathrm{a}}$, \\ Avik Bhattacharya ${ }^{a}$, Juan M. Lopez-Sanchez ${ }^{\mathrm{c}}$, Heather McNairn ${ }^{\mathrm{d}}$, \\ Yalamanchili S. Rao ${ }^{a}$ \\ ${ }^{a}$ Microwave Remote Sensing Lab, Centre of Studies in Resources Engineering, \\ Indian Institute of Technology Bombay, Mumbai, India \\ ${ }^{b}$ Department of Water Resources, Delft University of Technology, Delft, The Netherlands \\ ${ }^{c}$ Institute for Computer Research, University of Alicante, Alicante, Spain \\ ${ }^{d}$ Ottawa Research and Development Centre, Agriculture and Agri-Food Canada, Ottawa, \\ Canada
}

\begin{abstract}
Sentinel-1 Synthetic Aperture Radar (SAR) data has provided an unprecedented opportunity for crop monitoring due to its high revisit frequency and wide spatial coverage. The dual-pol Sentinel-1 SAR data is being utilized for the European Common Agricultural Policy (CAP) as well as for other national projects, which aim to provide Sentinel derived information to support crop monitoring networks. Among the several earth observation products identified for agriculture monitoring, the vegetation status indicator is one of the critical elements that require minimum end-user expertise. In literature, several experiments usually utilize the backscatter intensities to characterize crops. In this work, we jointly use both the scattered and received wave information to derive a new vegetation index (DpRVI) for Sentinel-1 dual-pol (VV-VH) SAR data. The DpRVI is derived using the degree of polarization
\end{abstract}

\footnotetext{
*Corresponding author: Dipankar Mandal (dipankar.agrilengg@gmail.com)
} 
and the dominant normalized eigenvalue obtained from the $2 \times 2$ covariance matrix. We assess the utility of this index as an indicator of plant growth dynamics over a test site in Carman, Canada. Among the various crops grown in this region, in particular, we analyze growth stages of canola, soybean, and wheat, considering their diverse canopy structures. A temporal analysis of DpRVI with crop biophysical variables (viz., Plant Area Index - PAI, Vegetation Water Content - VWC, and dry biomass-DB) at different phenological stages confirms its trend with plant growth dynamics. The DpRVI is compared for three crops with the cross and co-pol ratio $\left(\sigma_{\mathrm{VH}}^{0} / \sigma_{\mathrm{VV}}^{0}\right)$ and dual-pol Radar Vegetation Index $\left(\mathrm{RVI}=4 \sigma_{\mathrm{VH}}^{0} /\left(\sigma_{\mathrm{VV}}^{0}+\sigma_{\mathrm{VH}}^{0}\right)\right)$. Correlation analysis with biophysical variables shows that the DpRVI outperforms the other two vegetation indices with significant correlations coefficient for all three crops. For canola, DpRVI indicated the highest correlation with its biophysical variables, having a coefficient of determination $\left(R^{2}\right)$ of 0.79 (PAI), 0.82 (VWC), and 0.75 (DB). Moreover, DpRVI showed a moderate correlation $\left(R^{2} \gtrsim 0.6\right)$ with the biophysical parameters of wheat and low biomass soybean.

Keywords: Rice, degree of polarization, RVI, PAI, DpRVI, vegetation water content

\section{Introduction}

Crop growth condition monitoring is a principal element for production 3 risk estimates at a large spatial extent. Remote sensing techniques are known 4 to provide operational crop monitoring techniques to understand crop dynamics at a local and regional level. Although optical remote sensing has 6 been successfully used in such an operational framework (e.g., MODIS veg- 
etation products), these systems are restricted to data acquired under clear sky conditions. In this context, synthetic aperture radar (SAR) data are of significant interest for agricultural applications due to the ability of SAR systems to monitor crops under all weather conditions, and the sensitivity of the microwave signal to the dielectric and geometrical properties of the target (McNairn and Shang, 2016; Steele-Dunne et al., 2017). In particular, the availability of dual-pol SAR datasets from the operational Sentinel-1 mission presented a unique opportunity for the remote sensing application community (ESA, 2017). Dual-pol modes have advantages over full-pol acquisitions in terms of larger swath width and less data volume at the expense of limited polarimetric information (Lee et al., 2001; Ainsworth et al., 2009).

The Sentinel-1 dual-pol mode (VV-VH), refers to the transmission of a vertically polarized wave with the simultaneous reception of vertical and horizontal polarization. Hence, the received wave in co- and cross-polarized channels (VV-VH) provides information about a target directly in terms of backscatter intensities. Several studies utilized the backscatter intensities for identification of crop types (Kussul et al., 2016; Nguyen et al., 2016; Bargiel, 2017; Van Tricht et al., 2018; Mandal et al., 2018b; Whelen and Siqueira, 2018) and crop biophysical parameter estimation (Bousbih et al., 2017; Kumar et al., 2018; Mandal et al., 2018a). The sensitivity of backscatter intensities to crop phenology and morphological development led to developing crop monitoring framework solely with scattering powers Nelson et al. 2014; Nguyen et al., 2016; Lasko et al., 2018; Singha et al., 2019; Fikriyah et al. 2019).

Several efforts were attempted to derive vegetation metrics from SAR 
data using backscatter intensity ratios. Blaes et al. (2006) investigated the sensitivity of $\sigma_{\mathrm{VH}}^{0} / \sigma_{\mathrm{VV}}^{0}$ with the growth dynamics of maize plant. At high incidence angle $\left(35-45^{\circ}\right), \sigma_{\mathrm{VV}}^{0} / \sigma_{\mathrm{VH}}^{0}$ is sensitive to plant growth until the leaf area index (LAI) and vegetation water content (VWC) reach $4.90 \mathrm{~m}^{2} \mathrm{~m}^{-2}$ ) and $5.6 \mathrm{~kg} \mathrm{~m}^{-2}$, respectively. Later, this ratio is aptly utilized for crop type classification (McNairn et al., 2009; Inglada et al., 2016; Denize et al., 2019), phenology estimation (McNairn et al., 2018; Canisius et al., 2018), and vegetation characterization (Veloso et al., 2017; Vreugdenhil et al., 2018; Khabbazan et al., 2019). Veloso et al. (2017) noticed that this ratio was relatively stable during pre-cultivation stages and increased significantly at the tillering stages of cereal crops (wheat and barley). The $\sigma_{\mathrm{VH}}^{0} / \sigma_{\mathrm{VV}}^{0}$ ratio is better correlated to the fresh biomass of cereals and Normalized Difference Vegetation Index (NDVI) than the individual channel backscatter response. Besides, this ratio indicates better separability of maize, soybean, and sunflower during their heading/flowering stages.

․ The quad-pol Radar Vegetation Index (RVI) proposed by Kim and van Zyl (2009), was modified for dual-pol SAR data (Trudel et al., 2012) as, $4 \sigma_{\mathrm{HV}}^{0} /\left(\sigma_{\mathrm{HH}}^{0}+\sigma_{\mathrm{HV}}^{0}\right)$. Later with Sentinel-1 like dual-pol data (VV-VH), few studies used the alternative formulation as, $4 \sigma_{\mathrm{VH}}^{0} /\left(\sigma_{\mathrm{VV}}^{0}+\sigma_{\mathrm{VH}}^{0}\right)$ Nasirzadehdizaji et al., 2019; Gururaj et al., 2019). Nevertheless, these studies are driven by the utilization of the cross-polarized component of the received wave. Periasamy (2018) proposed the Dual Polarization SAR Vegetation Index (DPSVI) by investigating the physical scattering behavior of several targets (vegetation, soil, urban area, and water) in co- and cross-pol channels of Sentinel-1. It calculates the rate of depolarization in terms of the verti- 
cal dual depolarization index, $\left(\sigma_{\mathrm{VV}}^{0}+\sigma_{\mathrm{VH}}^{0}\right) / \sigma_{\mathrm{VV}}^{0}$ to separate bare soil from vegetation. The DPSVI indicated high $R^{2}$ values $(>0.70)$ with both optical data-driven NDVI and above-ground biomass. Chang et al. (2018) utilized the degree of polarization parameter (average of $\mathrm{HH}$ and VV channel degree of polarizations) along with the cross-pol backscatter intensity to characterize vegetation from bare soil. It may be noted that utilizing the scattered wave information in terms of the roll-invariant degree of polarization $(\mathrm{m})$ would enhance target characterization (Shirvany et al., 2012; Touzi et al., 2015, 2018).

Chang et al. (2018) utilized the degree of polarization of partially polarized waves for deriving a vegetation index (PRVI) for quad-pol SAR data. Assuming vegetation canopy as a depolarizing media, they first obtained the depolarized part by subtracting the degree of polarization from unity (i.e., $(1-m))$, subsequently multiplying it with the cross-polarization channel intensity $\left(\sigma_{H V}^{0}\right.$ in $\left.\mathrm{dB}\right)$. This approach showed a good correlation of PRVI with shrubland biomass $\left(R^{2}=0.75\right)$ than RVI $\left(R^{2}=0.50\right)$, which usually develops random structures within the vegetation canopy. However, agricultural crops often exhibit a predefined orientation (e.g., vertical or horizontal based on erectophiles and planophiles) and row structures. In this sense, only relying on cross-polarized power may lead to issues related to backscatter intensity saturation. Hence, utilizing $\mathrm{HV}$ (or $\mathrm{VH}$ ) may falsely indicate a high value of the vegetation index, even though the vegetation canopy is not entirely developed. An alternative would be to utilize the dominant scattering component (in terms of the eigenvalue spectrum of the covariance matrix) while calculating the polarized components. 
In this present work, we utilize the dual-pol Sentinel-1 SAR data to derive a new radar vegetation index (DpRVI) for crop condition monitoring. The eigenvalue spectrum obtained from the eigen-decomposition of the dualpol covariance matrix and the degree of polarization is used to derive this new index. Instead of utilizing the polarization channel backscatter intensities (Chang et al., 2018; Periasamy, 2018), the proposed index utilizes the normalized dominant eigenvalue and the degree of polarization which are roll and polarization basis invariant. Moreover, DpRVI is a bounded quantity (between 0 and 1), unlike PRVI, which uses the channel intensity in decibel, making it unbounded. We assess the utility of the dual-pol radar vegetation index (DpRVI) as an indicator of plant growth dynamics over the Joint Experiment for Crop Assessment and Monitoring (JECAM) test site in Carman (Manitoba), Canada. We perform a comparative analysis between DpRVI, $\sigma_{\mathrm{VH}}^{0} / \sigma_{\mathrm{VV}}^{0}$, and dual-pol RVI for three structurally diverse crop types. We further assess the temporal response of DpRVI to vegetation dynamics by comparing them with the in-situ measured vegetation biophysical parameters, such as Plant Area Index (PAI), Vegetation Water Content (VWC), and Dry biomass (DB).

\section{Study area and dataset}

The present study is carried over the Joint Experiment for Crop Assessment and Monitoring (JECAM) test site in Carman, Manitoba (Canada), as shown in Fig. 1. The test site covers approximately $26 \times 48 \mathrm{~km}^{2}$ of the area and is characterized by various agricultural crop types and soil conditions. The major annual crops grown in this area include wheat, canola, soybeans, 

ment (SMAPVEX16-MB) campaign in 2016 (Bhuiyan et al., 2018).

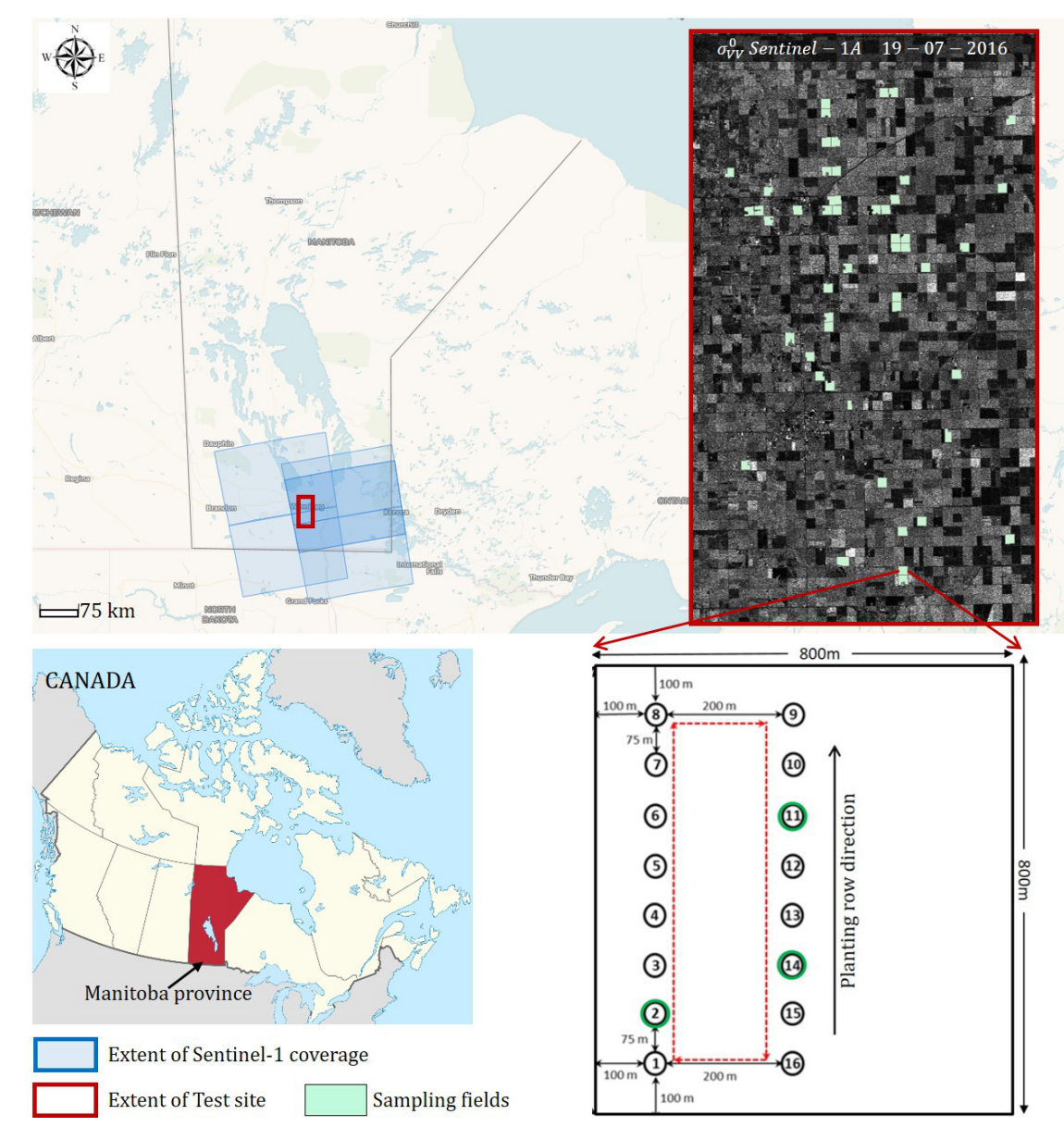

Figure 1: Study area (red box) and Sentinel-1 passes (blue boxes) over the Carman JECAM test site. The sampling fields (mint green polygons) are overlayed on $\sigma_{V V}^{0}$ Sentinel-1A image of 19 July, 2016. A layout of 16 sampling locations within a field is highlighted.

corn, and oats. Only a small fraction $(<5 \%)$ is under grassland and pasture. The in-situ measurements were collected over the area near coincident with satellite passes during the Soil Moisture Active Passive Validation Experi-

During the campaign, in-situ measurements of vegetation and soil were collected in two distinct periods (June 08 to June 22, and July 8 to July 22, 

square meter area.
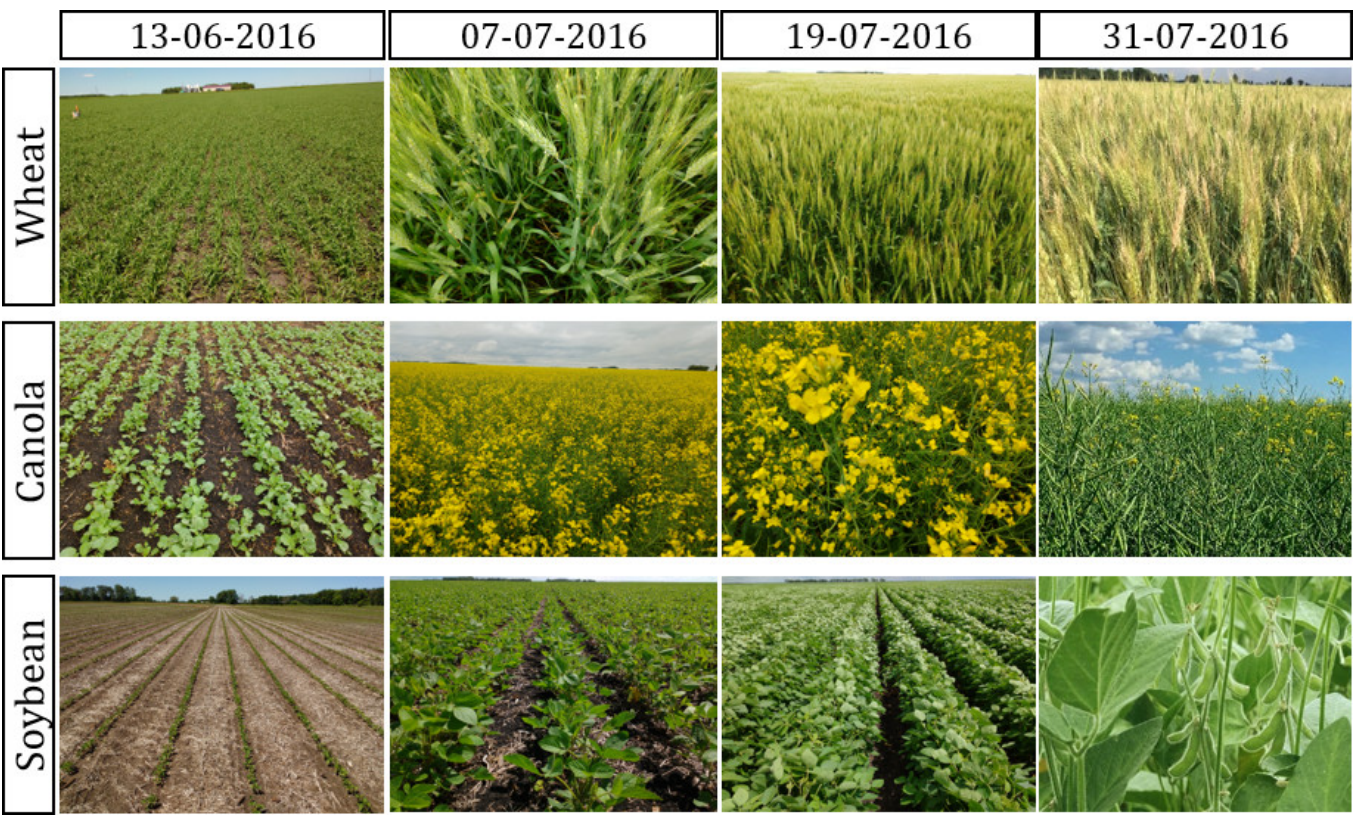
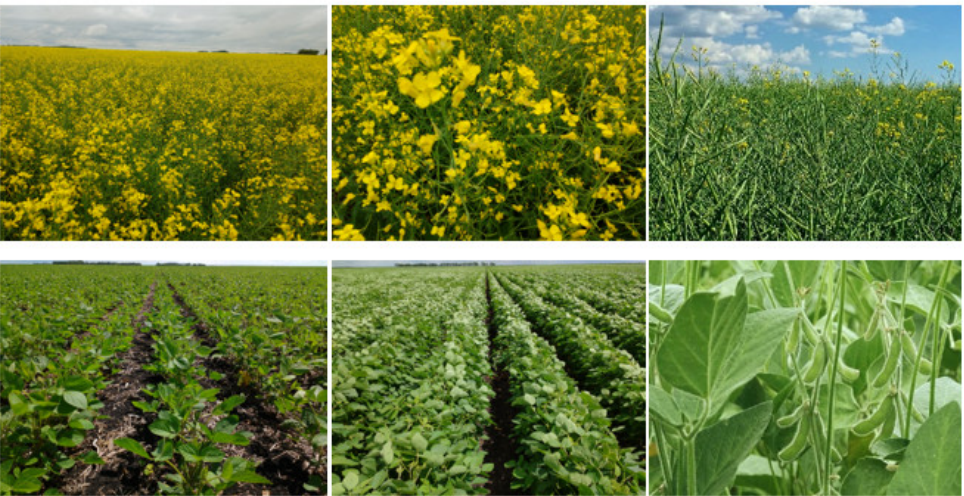

2016) over 50 agricultural fields. During this experimental period, most of the crops advanced from an early stage to a peak accumulation of biomass at the full vegetative stage, as shown in Fig. 2. The nominal size of each field is approximately $800 \mathrm{~m} \times 800 \mathrm{~m}$. In each sampling field, three points were selected for vegetation sampling, as shown in Fig. 1, which included measurement of plant area index (PAI), wet and dry biomass, plant height, and phenological stages through destructive and non-destructive sampling methods (McNairn et al. 2016). The biomass measurements are used to derive the vegetation water content (VWC) and dry biomass (DB) per unit

Figure 2: Field condition during the campaigns for wheat, canola, and soybean crops. 
et al. 2016). Among several Sentinel-1 acquisitions during the campaign, four dual polarization (VV and VH) C-band Sentinel-1A Single Look Complex (SLC) data used in this study, as given in Table 1. The selection of Sentinel1 data is solely based on acquisition dates and in-situ measurements periods.

Table 1: Sentinel-1A acquisitions over Carman test site during the field campaign

\begin{tabular}{cccc}
\hline $\begin{array}{c}\text { Acquisition } \\
\text { date }\end{array}$ & Beam Mode & $\begin{array}{c}\text { Incidence Angle } \\
\text { Range (deg.) }\end{array}$ & Orbit \\
\hline $13 / 06 / 2016$ & IW & $31.32-35.24$ & Ascending \\
$07 / 07 / 2016$ & IW & $31.12-35.54$ & Ascending \\
$19 / 07 / 2016$ & IW & $31.12-35.54$ & Ascending \\
$31 / 07 / 2016$ & IW & $31.12-35.54$ & Ascending \\
\hline
\end{tabular}

\section{Methodology}

\section{1. $S A R$ data preprocessing}

Sentinel-1 acquires data over land majorly in the Terrain Observation with Progressive Scans SAR (TOPSAR) mode and delivers the Level-1 SLC data in Interferometric Wide (IW) product. A full swath covers approximately $250 \mathrm{~km}$ length at $5 \times 20 \mathrm{~m}$ spatial resolution in single look. The IW swath consists of three sub-swaths (IW1, IW2, and IW3) in the range direction. Each sub-swaths has 9 bursts in the azimuth direction, and the individually focused complex bursts are arranged in azimuth-time order with black-fill in between. For further applications, these SLC products are preprocessed with a standard set of corrections in a workflow, as shown in Fig. 3. 


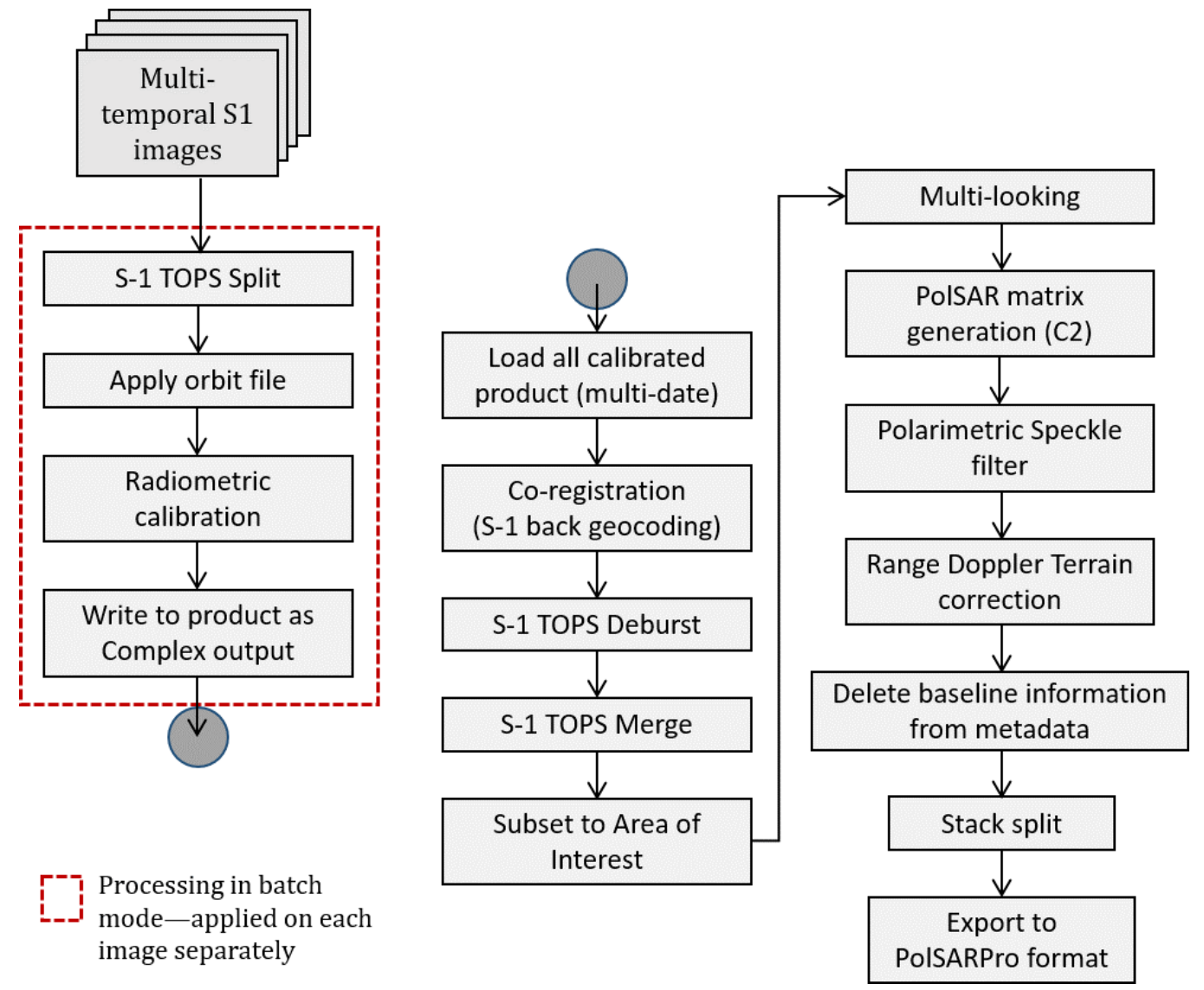

Figure 3: Sentinel-1 preprocessing workflow for time-series data.

The present study involves preprocessing of the temporal dataset to obtain the $2 \times 2$ covariance matrices. Individual Sentinel- 1 images are read into the SNAP7.0 tool (ESA, 2015) provided by ESA. The sub-swaths and bursts are then selected based on the test area coverage with TOPS Split module. A precise orbit file is applied to update the state vectors, and subsequently, the images are calibrated. Unlike the GRD processing pipeline, which is used to generate the radar cross-section powers $\left(\sigma^{0}\right)$, the current workflow requires saving the radiometric calibration output product in a complex-valued for- 
mat. A complex-values output is necessary to generate the covariance matrix in succeeding steps. These processing steps are performed in a batch mode for all temporal datasets.

All these calibrated images from different dates are coregistered using the S-1 Back Geocoding module to generate a stack of coregistered data. This interferometric coregistration module coregisters all the SLC images with sub-pixel accuracy using a digital elevation model (DEM) and orbit information. Subsequently, the stack of temporal images is processed for Sentinel-1 TOPS Deburst and TOPS Merge, which merges different bursts of an individual image (of a particular date) into a single SLC image. Subset operation is then performed on the debursted image to clip the product into smaller spatial extent covering the test area.

The subset stacked images are multilooked by $4 \times 1$ in range and azimuth direction to generate ground ranged square pixels. These multi-looked products are then utilized to produce a $2 \times 2$ covariance matrix $\left(\mathbf{C}_{2}\right)$. The matrix elements are further processed by despeckling them with a $5 \times 5$ Refined Lee filter. These elements are subsequently geocoded to a UTM projected coordinate systems using the Range Doppler Terrain correction. The next step requires the deletion of baseline information from the metadata, which is essential for exporting the covariance matrices from SNAP to PolSARPro format. The stack is then split into individual products using Stack Split operator, and these products (i.e., the $2 \times 2$ covariance matrices for single dates) are exported into the PolSARPro format. It stores each matrix elements $\left(C_{11}, C_{22}, \Re\left(C_{12}\right)\right.$, and $\left.\Im\left(C_{12}\right)\right)$ individually in a binary format with separate header information. These elements essentially deal with the second-order 
scattering information generated from the spatial averaging of the scattering vector $k=\left[S_{V V}, S_{V H}\right]^{T}$ as expressed in (1),

$$
\mathbf{C}_{2}=\left[\begin{array}{cc}
C_{11} & C_{12} \\
C_{21} & C_{22}
\end{array}\right]=\left[\begin{array}{cc}
\left\langle\left|S_{V V}\right|^{2}\right\rangle & \left\langle S_{V V} S_{V H}^{*}\right\rangle \\
\left\langle S_{V H} S_{V V}^{*}\right\rangle & \left\langle\left|S_{V H}\right|^{2}\right\rangle
\end{array}\right]
$$

where superscript ${ }^{*}$ denotes complex conjugate and $\langle\cdots\rangle$ denotes spatial average over a moving window.

\subsection{Dual-pol Radar Vegetation Index (DpRVI)}

Radar backscatter intensity provides information about spatial and temporal variations in crop growth and their phenology stages. Hence, assimilating time-series SAR data for crop growth monitoring could improve risk assessment. A reasonable step in this regard would be to derive various vegetation metrics from SAR data. While utilizing the characteristic of scattering randomness from vegetation structure, few studies proposed radar vegetation indices viz., RVI (Kim and van Zyl, 2009), and GRVI (Mandal et al., 2020) for full-pol SAR data to provide a relatively simple and physically interpretable vegetation descriptor. Even though these radar vegetation indices are a good proxy for vegetation condition, they are confined to the use of full-polarimetric SAR data. Hence, there is a need to devise a vegetation index for dual-pol SAR data (viz., Sentinel-1).

In this study, we have jointly utilized the scattering information in terms of the degree of polarization and the eigenvalue spectrum to derive a new vegetation index from dual-pol SAR data. The state of polarization of an EM wave is characterized in terms of the degree of polarization $(0 \leq m \leq 1)$.

The degree of polarization is defined as the ratio of the (average) intensity of 
the polarized portion of the wave to that of the (average) total intensity of the wave. For a completely polarized EM wave, $m=1$ and for a completely unpolarized EM wave, $m=0$. In between these two extreme cases, the EM wave is assumed to be partially polarized, $0<m<1$.

Barakat (Barakat, 1977) provided an expression of $m$ for the $N \times N$ covariance matrix. This expression is used in this study to obtain the degree of polarization $m$ from the $2 \times 2$ covariance matrix $\mathbf{C}_{2}$ for dual-pol data as,

$$
m=\sqrt{1-\frac{4\left|\mathbf{C}_{2}\right|}{\left(\operatorname{Tr}\left(\mathbf{C}_{2}\right)\right)^{2}}}
$$

where $\mathrm{Tr}$ is the matrix trace operator (i.e., the sum of the diagonal elements) and $|\cdot|$ is the determinant of a matrix. The two non-negative eigenvalues $\left(\lambda_{1} \geq \lambda_{2} \geq 0\right)$ are obtained from the eigen-decomposition of the $\mathbf{C}_{2}$ matrix which are then normalized with the total power Span $\left(\operatorname{Tr}\left(\mathbf{C}_{2}\right)=\lambda_{1}+\lambda_{2}\right)$. These two quantities are then utilized to derive the dual-pol radar vegetation index (DpRVI) as given in (3).

$$
\mathrm{DpRVI}=1-\mathrm{m} \cdot \beta, \quad 0 \leq \mathrm{DpRVI} \leq 1,
$$

where $\beta=\lambda_{1} /$ Span.

The rationale behind the joint utilization of $m$ and $\beta$ is inherited from their differential sensitivity to crop growth dynamics. The variations in scattering mechanisms associated with the phenological growth stages are combined in the present study through these two parameters. The experimental plots shown in Fig. 4 4indicate their variations through temporal growth stages for three different crops. 

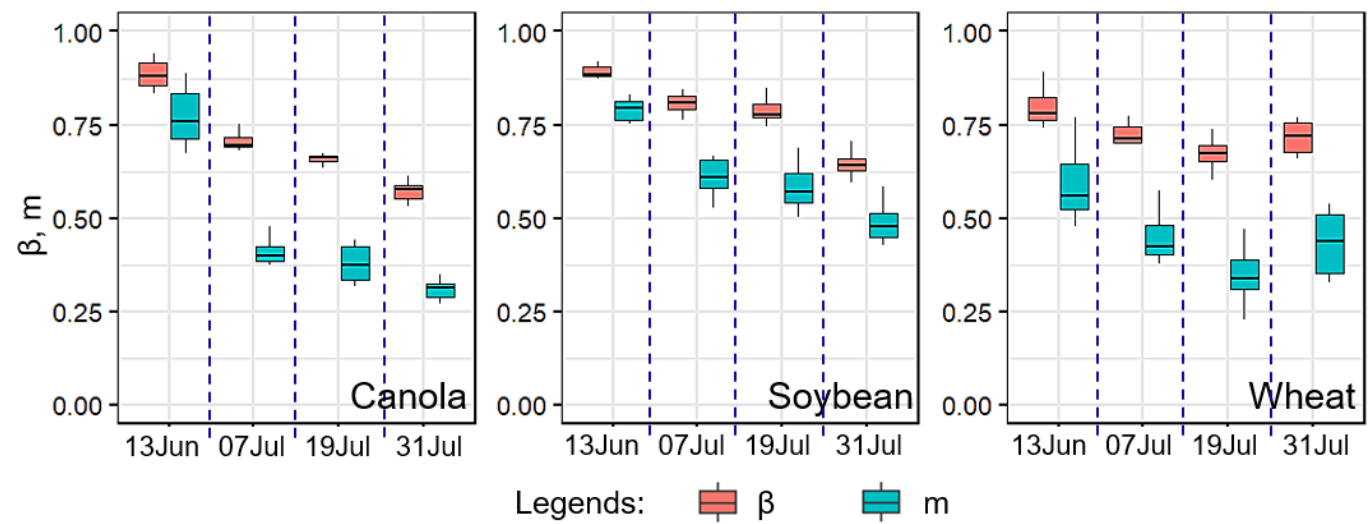

Figure 4: Sensitivity of $m$ and $\beta$ parameter in temporal scale for individual crops.

Even though these parameters are investigated in detail in Sec. 4, here, we briefly highlight their individual importance to characterize the proposed index. This insight is particularly vital considering their differential changes within a distinctive dynamic range at several phenological stages. For example, the mean values of $m$ and $\beta$ decrease with the growth stages of canola (Fig. 4). It is interesting to note that both $m$ and $\beta$ are $>0.70$ with a marginal difference between their values on 13 June. However, this difference increases as canola advances through its phenology to full vegetative growth during the 3rd week of July. Similarly, for soybean and wheat, the differential sensitivities of $m$ and $\beta$ are apparent throughout its growth stages, as shown in Fig. 4. It is interesting to note that unlike other crops, wheat shows an increasing trend in both $m$ and $\beta$ during the end of the ripening stage on 31 July, with higher variations. Such a difference may be due to a high degree of randomness in scattering from wheat heads. Besides, during the end of the ripening stage (i.e., when the heads and tillers become drier), there could be a notable backscatter contribution from the ground, which 
indicates higher values of $\beta$.

It can be observed from the general analysis of the eigenvalue spectrum (given in Appendix A) that these differential variations between $m$ and $\beta$ are related to $\lambda_{2} /$ Span. This quantity is related to the noise associated with the less dominant scattering mechanism. Usually, at the early stage of plant development, there exists a single dominant scattering mechanism from the bare soil, thereby showing a low difference between $m$ and $\beta$.

The elements of DpRVI (i.e., $m$ and $\beta$ ) are shown in a polar plot (Fig. 5). This type of representation is adopted in this study to better comprehend subtle variations in the scattering characteristics during the transition of phenological stages. In this plot, $\cos ^{-1} \beta$ is represented in the angular direction, while $m$ is the radial axis. In this study, the polar plot is used to characterize temporal variations in the scattering attributes for each crop type, individually discriminated by $m$ and $\beta$. Besides, elementary targets are shown to be located at the extremities of the boundaries, while natural targets reside within the polar plot.

The $\beta$ parameter indicates the contribution of the dominant scattering component withing the total power. For pure or point target scattering with a dominant scattering mechanism, $\beta=1$ which assigns to $\cos ^{-1} \beta=0^{\circ}$ with $m=1$ in the polar plot. This state corresponds to Case- 2 shown in Fig. 5 with DpRVI $=0$. Theoretically, for a smooth bare surface (i.e., Bragg scattering), $\lambda_{1} \gg \lambda_{2}$ with a high value of $m$ pointing to $\cos ^{-1} \beta \approx 0$. However, the cluster density plot of bare soil indicates variations in $m$ and $\cos ^{-1} \beta$ about their respective extremes, which is possible for natural surfaces.

In the case of completely random scattering (i.e., with no polarization 

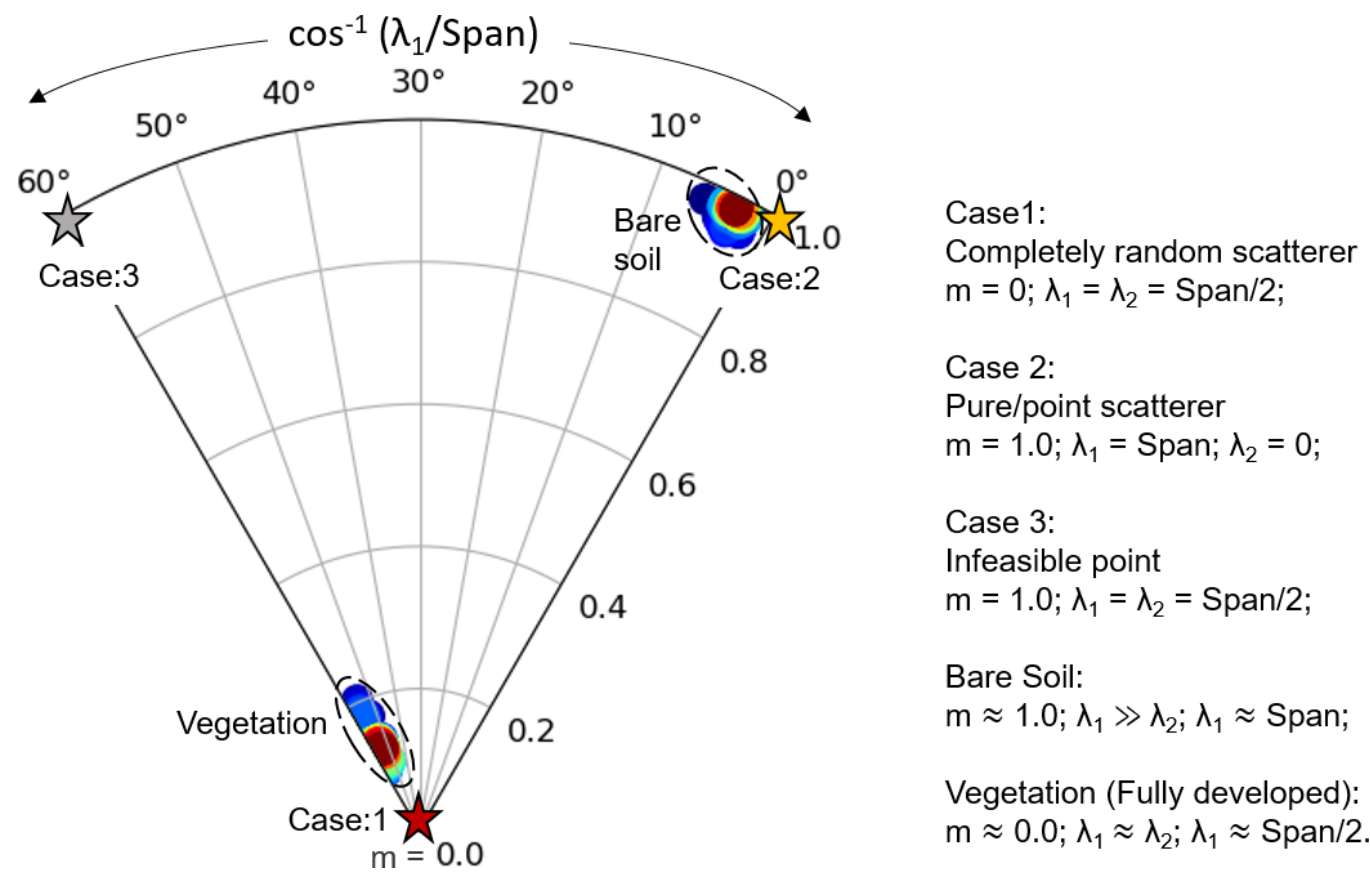

Figure 5: The elements of DpRVI i.e., degree of polarization $(m)$ and $\beta$ (i.e., $\lambda_{1} /$ Span) in polar plot. The $\cos ^{-1} \beta$ is represented in the angular direction and $\mathrm{m}$ in radial axis of the polar plot. The boundary cases and regions of natural targets are highlighted. The vegetation and soil clusters are derived using radar measurements over the sampling fields.

structure), $m=0$ (i.e., completely depolarized wave) and $\beta=0.5$. This suggests that $\lambda_{1}=\lambda_{2}=\operatorname{Span} / 2$ for which DpRVI $=1$. Case-1 is a typical example of such a state. However, for natural targets like fully developed vegetation canopy, $m \approx 0$ and $\beta \approx 0.5$, leading to higher DpRVI, i.e., $\mathrm{DpRVI} \approx 1$. Moreover, dispersion of $m$ and $\beta$ in the density plot is evident in the vegetation cluster. As plant canopy advances from early leaf development to fully vegetative stage, the DpRVI increases from 0 to 1.

It can be noted that at each phenological stage, $m$ and $\beta$ is denoted as points in the polar plot. However, certain regions in the $m-\beta$ plot are infeasible due to the non-existence of physical depolarizers in such regions. 
Case-3 is an instance of such a state, where $m=1.0$ (i.e., pure target) and $\cos ^{-1} \beta=60^{\circ}$, indicating, $\lambda_{1}=\lambda_{2}=\operatorname{Span} / 2$ (i.e., similar to a complete depolarizer). These types of targets are not practically possible in natural scenarios.

\subsection{Data analysis and comparison}

Elements of the $\mathbf{C}_{2}$ matrix are used to calculate the DpRVI as discussed in Sec. 3 for each acquisition over a $5 \times 5$ window. In addition, the DpRVI is compared with the cross and co-pol ratio $\left(\sigma_{V H}^{0} / \sigma_{V V}^{0}\right)$ and the RVI $\left(4 \sigma_{\mathrm{VH}}^{0} /\left(\sigma_{\mathrm{VV}}^{0}+\sigma_{\mathrm{VH}}^{0}\right)\right.$. These parameters are computed from the diagonal elements of the $\mathbf{C}_{2}$ matrix. The in-situ measurement points (i.e., the vector file) are overlayed on the temporal $\sigma_{V H}^{0} / \sigma_{V V}^{0}$, and RVI and DpRVI images. Here it is important to note that the nominal field size of the study area is relatively bigger (approx. $800 \mathrm{~m} \times 800 \mathrm{~m}$ ) than the size of the image pixel (approx. $15 \mathrm{~m} \times 15 \mathrm{~m}$. Hence, the vegetation indices for each sampling location are calculated as an average over a $3 \times 3$ window centered on each site.

These parameters are initially investigated on a temporal scale for various phenological stages of crops. We have selected three structurally different crops for this study: wheat, canola, and soybean. The temporal behaviour of these parameters are also compared with crop biophysical variables, such as the plant area index (PAI, $\left.\mathrm{m}^{2} \mathrm{~m}^{-2}\right)$, dry biomass $\left(\mathrm{DB}, \mathrm{kgm}^{-2}\right)$, and vegetation water content $\left(\mathrm{VWC}, \mathrm{kgm}^{-2}\right)$. Finally, the DpRVI, $\sigma_{V H}^{0} / \sigma_{V V}^{0}$, and RVI are utilized in a correlation analysis with these crop biophysical variables. 


\section{Results and discussion}

This section describes the results of the proposed vegetation index-DpRVI separately for three crop types, viz., canola, soybean, and wheat. Besides, the comparative investigation of DpRVI, $\sigma_{V H}^{0} / \sigma_{V V}^{0}$, and dual-pol RVI are assessed along with crop biophysical parameters in this section.

\subsection{Canola}

The temporal analysis of DpRVI averaged for three sampling points in each canola fields (Field no. 206, 208, and 224) are shown in Fig. 6. For comparative analysis, $\sigma_{V H}^{0} / \sigma_{V V}^{0}$ and RVI for these fields are presented. Furthermore, a regression analysis is performed for the vegetation indices with in-situ measured PAI, VWC, and dry biomass (Fig. 8).

The in-situ measurements indicate that canola seeding was almost completed by the 3rd week of May. Thus, plant development during the beginning of June was primarily limited to vegetative growth. Subsequently, flowering started in the last week of June to early July, which led to pod development by the mid of July. Ripening of seeds and senescence followed at the end of July until the 2nd week of August. The phenological stages are highlighted in the temporal plots of vegetation indices for each field (Fig. 6). Analysis of canola, in particular, is interesting due to its dynamic morphological changes with phenology. Canola is a broad-leaf plant with distinctive differences in canopy structure throughout the growing season. Upon emergence, the plant develops a dense rosette of leaves near to the soil. Hence, the backscatter response is affected by the development of leaves, which have a similar size compared to C-band wavelength $(\approx 5.6 \mathrm{~cm})$. The canola stem then bolts, 

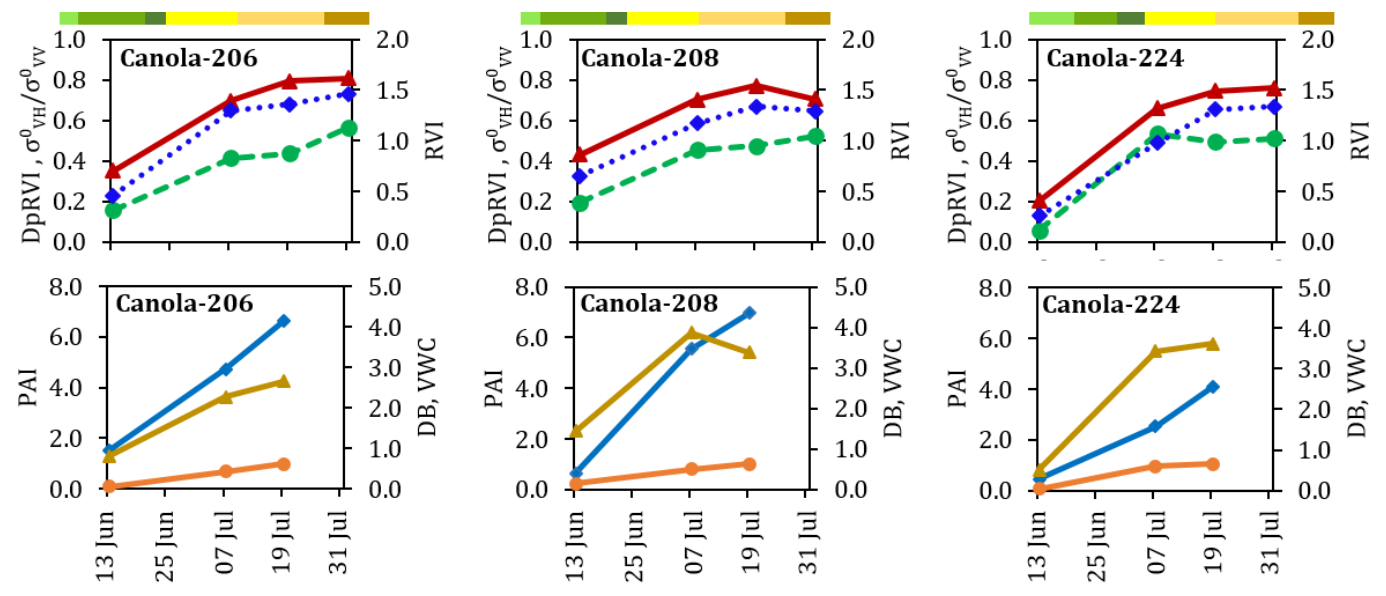

$\rightarrow$ DpRVI

$\sigma^{0}{ }_{\mathrm{VH}} / \sigma_{\mathrm{VV}}^{0} \quad \cdots \leftrightarrow \mathrm{RVI} \quad \longrightarrow \mathrm{PAI}$

$\leadsto$ DB $\multimap$ VWC

Leaf development - side shoot formation

Stem elongation

Inflorescence emergence

Flowering

Pod development

Ripening

Figure 6: Temporal pattern of vegetation indices (DpRVI, $\sigma_{V H}^{0} / \sigma_{V V}^{0}$ and RVI) for three representative canola fields at different growth stages. The in-situ measurements of Plant Area Index (PAI, $\mathrm{m}^{2} \mathrm{~m}^{-2}$ ), Vegetation water content (VWC, $\mathrm{kg} \mathrm{m}^{-2}$ ), and dry biomass $\left(\mathrm{DB}, \mathrm{kg} \mathrm{m}^{-2}\right)$ are plotted in second row for each field.

increasing its vertical structure just before flowering and podding with the increase in both PAI and biomass (Wiseman et al., 2014). Latter in the pod development stage, it usually forms a dense and complex canopy structure.

On 13 June, DpRVI is $\approx 0.35$ in the majority of the canola fields, indicating low vegetation content. In-situ measurements confirm that their growth was limited to the stem elongation stage with low PAI $\left(\approx 1.45 \mathrm{~m}^{2} \mathrm{~m}^{-2}\right)$ and biomass $\left(\mathrm{VWC}=1.0 \mathrm{~kg} \mathrm{~m}^{-2}\right.$ and $\mathrm{DB}<0.2 \mathrm{~kg} \mathrm{~m}^{-2}$ ). The vegetation cluster in the $m-\beta$ polar plot (Fig. 7 shows a high value of $m \approx 0.90$ along with a high value of $\beta\left(\cos 20^{\circ}=0.94\right)$ during early development stages with less random canopy structure. Similarly, a low value of $\sigma_{V H}^{0} / \sigma_{V V}^{0}$ and RVI also indicate sparse vegetation condition. In comparison to field 206 and 208, 

plants were still at their leaf development stage.

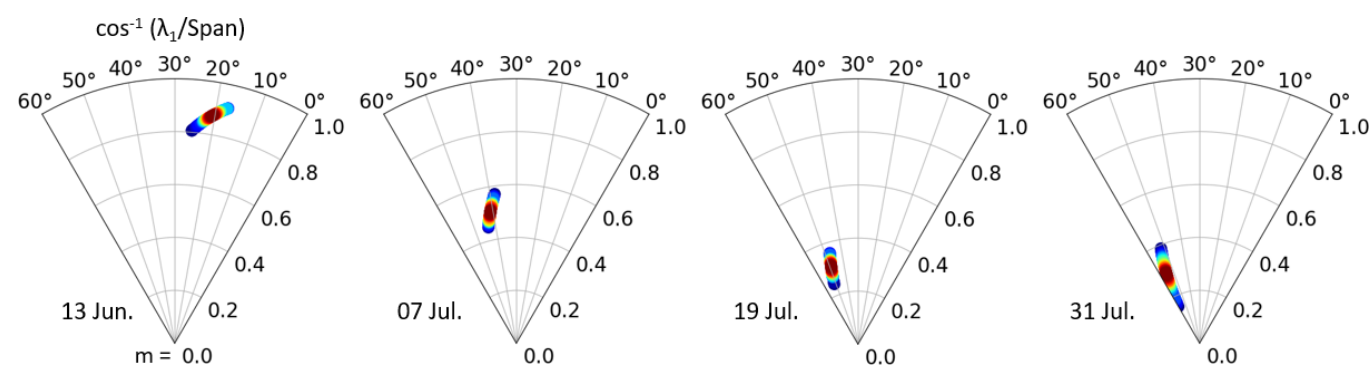

Figure 7: Temporal variations of degree of polarization $(\mathrm{m})$ and $\beta$ in polar plots for canola fields.

with low vegetation cover (i.e., $\mathrm{PAI} \approx 0.5 \mathrm{~m}^{2} \mathrm{~m}^{-2}$ ) and $\mathrm{VWC}<0.42 \mathrm{~kg} \mathrm{~m}^{-2}$ ), a lower value of DpRVI $(\approx 0.18)$ is apparent in field 224 , where the canola (1)

The DpRVI values for each field increased rapidly as the plant growth progresses from the early vegetative stage to the beginning of pod development. During the early pod development stage (19 July), the DpRVI is $\approx 0.8 \pm 0.04$. At high growth stages, with the increase of vegetation elements, a decrease in $m$ is likely due to the depolarization of incident waves from the complex vegetation canopy. During this pod development stage, the ramified stems and the randomly oriented pods create a complex upper canopy structure that may increase multiple scattering mechanisms. This aspect may lead to similar values of $\lambda_{1}$ and $\lambda_{2}$ (equal to Span/2). Variations in $m$ and $\beta$ with vegetation growth stages are apparent in Fig. 7. A significant increase in $\sigma_{V H}^{0} / \sigma_{V V}^{0}$ is observed during the inflorescence emergence and flowering stage. This event can be possibly explained by the changes in the cross-pol intensity as the canopy develops (Pacheco et al., 2016).

During the advanced pod development to ripening stage, the DpRVI val- 

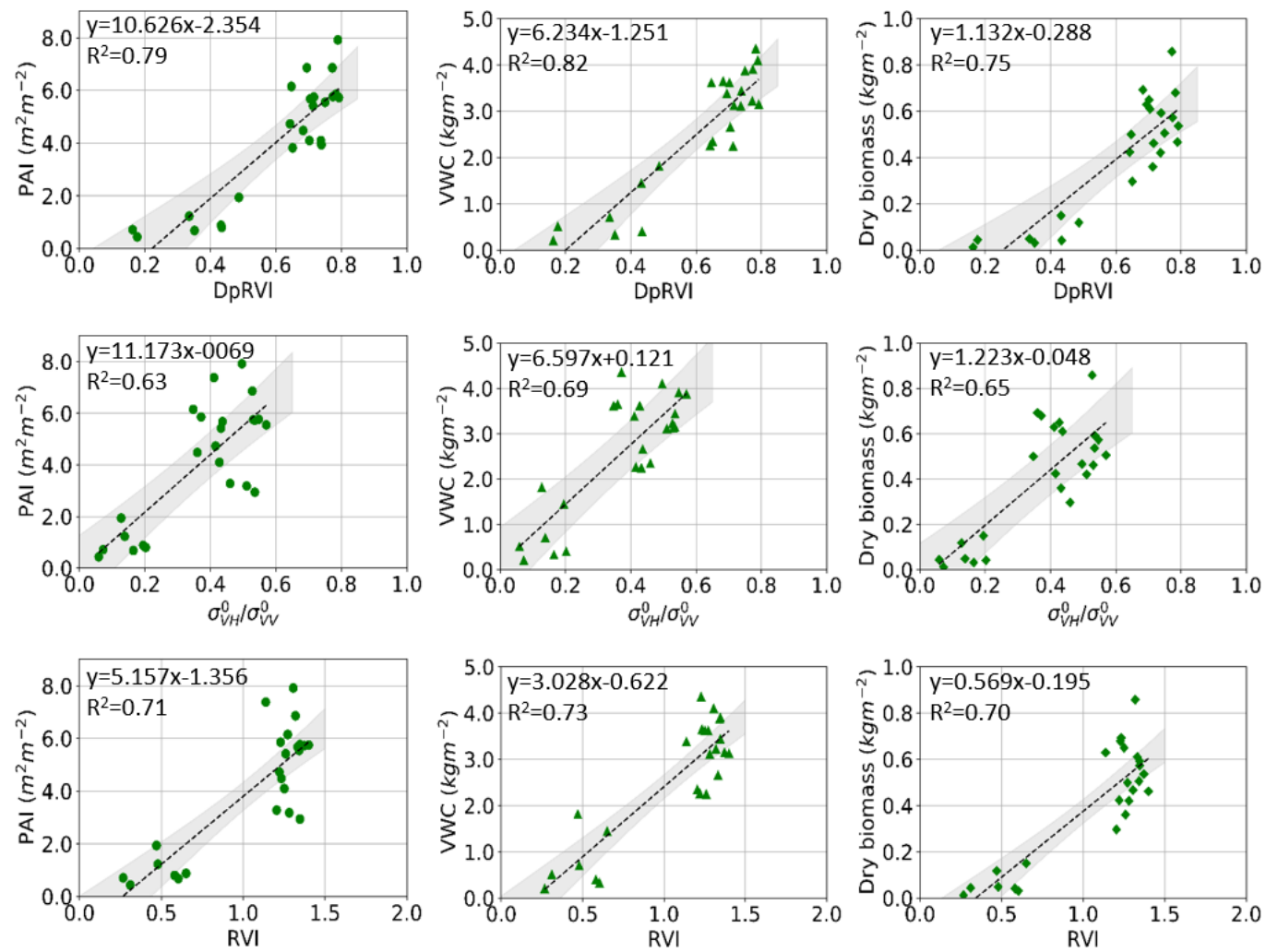

Figure 8: Correlation analysis between vegetation indices (DpRVI, $\sigma_{V H}^{0} / \sigma_{V V}^{0}$ and RVI) and crop biophysical parameters, i.e., Plant Area Index (PAI, $\mathrm{m}^{2} \mathrm{~m}^{-2}$ ), Vegetation water content (VWC, $\mathrm{kg} \mathrm{m}^{-2}$ ), and dry biomass $\left(\mathrm{DB}, \mathrm{kg} \mathrm{m}^{-2}\right.$ ) for canola. The linear regression line is indicated as black dashed line. The $95 \%$ confidence limits are highlighted as gray regions.

ues are peculiarly confined within the range of $0.75 \pm 0.05$, rather than increasing from the early pod development stages. At the end of the pod development stage, in-situ measurements indicate high vegetation cover $\left(\mathrm{PAI} \approx 6.0 \mathrm{~m}^{2} \mathrm{~m}^{-2}\right)$ and biomass (VWC $>3.0 \mathrm{~kg} \mathrm{~m}^{-2}$ and $\mathrm{DB} \approx 1.0 \mathrm{~kg} \mathrm{~m}^{-2}$ ). The sensitivity of the SAR signal to the accumulation of biomass from leaf development until the flowering stage is apparent in Fig. 6. Following this, a saturation of the C-band signal is likely due to the high volume of vegetation components dur- 
ing the pod development stage (Wiseman et al., 2014). Besides, the values of $\sigma_{V H}^{0} / \sigma_{V V}^{0}$ and RVI also remain stable at high growth stages. These results are comparable to the backscatter response from canola reported in Veloso et al. (2017); Vreugdenhil et al. (2018).

Furthermore, a quantitative assessment of vegetation indices is essential for comparative analysis. The correlation plots in Fig. 8 indicate that the DpRVI values are better correlated with the biophysical parameters of canola than $\sigma_{V H}^{0} / \sigma_{V V}^{0}$ and RVI. It is observed that the coefficients of determination $\left(R^{2}\right)$ for the PAI, VWC, and DB with DpRVI are $0.79,0.82$, and 0.75 respectively. Hence, it can be seen that in particular, $\sigma_{V H}^{0} / \sigma_{V V}^{0}$ and RVI showed a relatively lower correlation with PAI, VWC, and DB. The DpRVI indeed outperforms the other two vegetation indices with a stronger correlation, with low variance throughout the entire growth stages.

\subsection{Soybean}

Unlike cereal and oil-seed crops, soybean (belongs to the leguminous family of crops) has more planophile canopy architecture. However, at the high vegetative stage, the canopy develops a random structure. This is due to its unique morphology with trifoliate leaf (a compound leaf made of three leaflets) attached to each stem node with petiole, secondary stems, and randomly oriented leaves (Fehr et al., 1971).

The Manitoba weekly crop reports (Agriculture, 2016) suggests that soybean seeding was completed by the 3rd week of May. Thus, crop development during the beginning of the SMAPVEX-16 campaign in June was primarily restricted to vegetative growth. Subsequently, inflorescence emergence, flowering, and pod initiation started during the last week of July. The develop- 

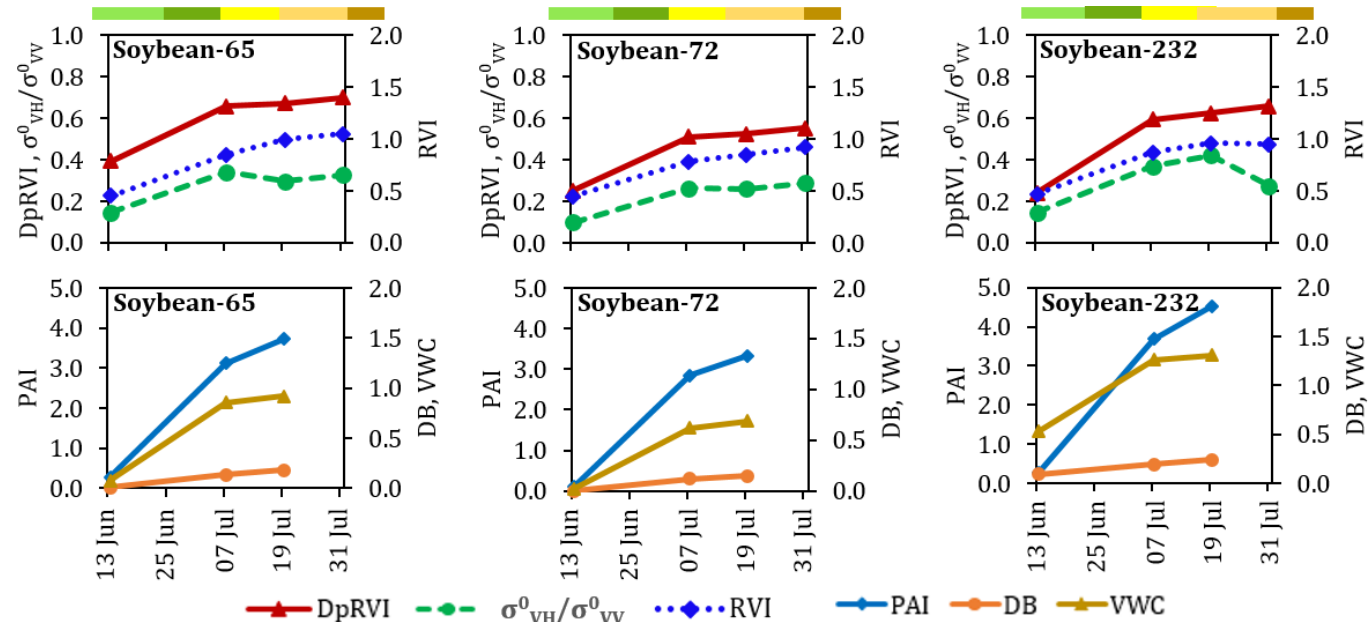

eaf development

$\sigma_{\mathrm{VH}}^{0} / \sigma_{\mathrm{VV}}^{0} \cdots \cdot \mathrm{RVI}$

$\because \mathrm{PAI} \rightarrow \mathrm{DB} \rightarrow \mathrm{VWC}$

Pod development

Side shoot formation

Inflorescence emergence--Flowering

Ripening

Figure 9: Temporal pattern of vegetation indices (DpRVI, $\sigma_{V H}^{0} / \sigma_{V V}^{0}$ and RVI) for three representative soybean fields at different growth stages. The in-situ measurements of Plant Area Index $\left(\mathrm{PAI}, \mathrm{m}^{2} \mathrm{~m}^{-2}\right.$ ), Vegetation water content $\left(\mathrm{VWC}, \mathrm{kg} \mathrm{m}^{-2}\right)$, and dry biomass $\left(\mathrm{DB}, \mathrm{kg} \mathrm{m}^{-2}\right.$ ) are plotted in second row for each field.

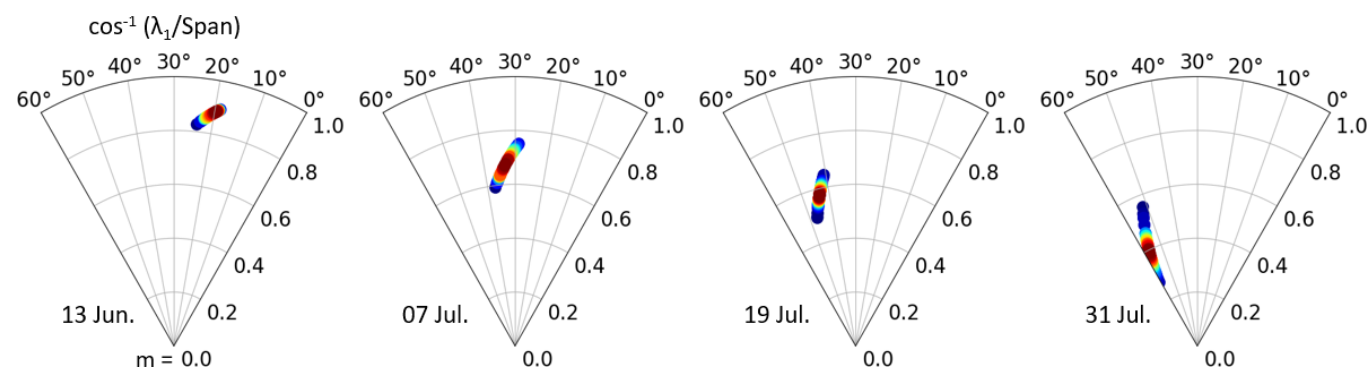

Figure 10: Temporal variations of degree of polarization $(\mathrm{m})$ and $\beta$ in polar plots for soybean fields.

ment of pods, ripening of seeds, and senescence followed in August until the 2nd week of September.

Fig. 9 shows the temporal trends of the vegetation indices for three rep- 
resentative fields (Field no. 65, 72, and 232). It is evident from Fig. 9 that the DpRVI values for each field increase rapidly as the vegetation growth increases from the early leaf development stage to the beginning of pod development. The DpRVI value is $\approx 0.21$ at the leaf development stage (on 13 June).

In-situ measurements confirm the vegetative growth with low PAI $\left(\approx 0.35 \mathrm{~m}^{2} \mathrm{~m}^{-2}\right)$ and biomass (VWC $=0.2 \mathrm{~kg} \mathrm{~m}^{-2}$ and $\mathrm{DB}<0.05 \mathrm{~kg} \mathrm{~m}^{-2}$ ). The $m-\beta$ polar plot (Fig. 10 indicates that the vegetation cluster lies in the region of high $m(\approx 0.90)$ and $\beta$ during early development stages (i.e., 2 nd trifoliate stage) with less random canopy structure. During this stage, the SAR backscatter is majorly affected by the underlying soil (Wang et al., 2016). It may be noted that a similar effect of soil on backscatter response at the early vegetative stage is also reported by Cable et al. (2014) with quad-pol RADARSAT2 SAR data. Alongside, low values of $\sigma_{V H}^{0} / \sigma_{V V}^{0}$ and RVI also indicate an early stage of vegetation growth. However, Veloso et al. (2017) reported a higher standard deviation of the co-pol channel than cross-pol for bare soil conditions, which may impart bias in $\sigma_{V H}^{0} / \sigma_{V V}^{0}$ and RVI values.

With the increase in vegetation components, the variations in DpRVI values among several fields are apparent. It reaches a high value $(\approx 0.55)$ at the end of the flowering stage. This stage indicates an increase in the volume scattering component. Moreover, biophysical parameters are high (PAI $>3.0 \mathrm{~m}^{2} \mathrm{~m}^{-2}$, VWC $>1.25 \mathrm{~kg} \mathrm{~m}^{-2}$, and DB $0.40 \mathrm{~kg} \mathrm{~m}^{-2}$ ) during this stage. Wigneron et al. (2004) indicated random scattering behaviour at high vegetative growth of soybean rather than a dominant scattering component. A significant increase in $\cos ^{-1} \beta$ along with a decrease in $m$ at the high vege- 

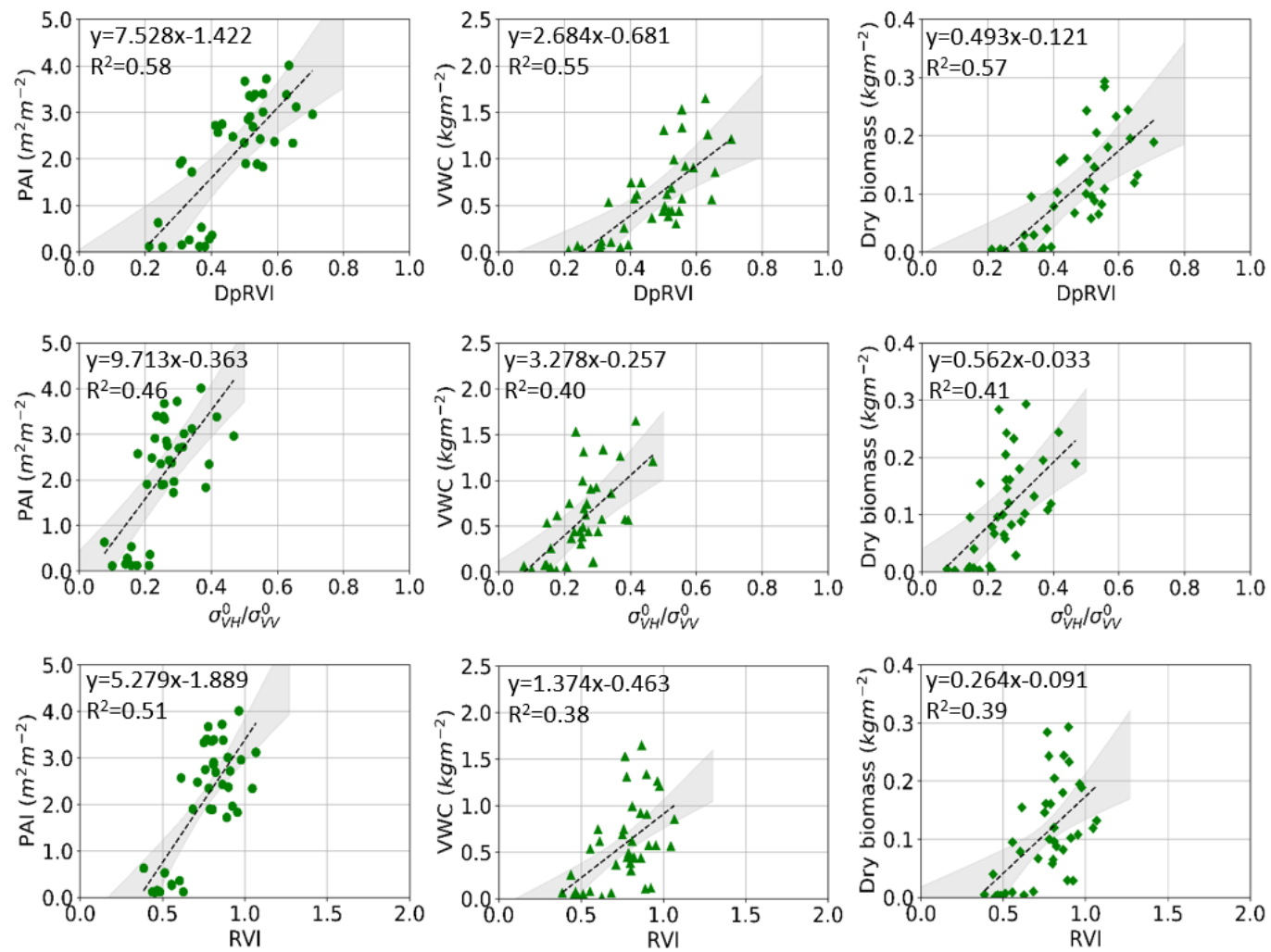

Figure 11: Correlation analysis between vegetation indices (DpRVI, $\sigma_{V H}^{0} / \sigma_{V V}^{0}$ and RVI) and crop biophysical parameters, i.e., Plant Area Index (PAI, $\left.\mathrm{m}^{2} \mathrm{~m}^{-2}\right)$, Vegetation water content (VWC, $\mathrm{kg} \mathrm{m}^{-2}$ ), and dry biomass $\left(\mathrm{DB}, \mathrm{kg} \mathrm{m}^{-2}\right.$ ) for soybean. The linear regression line is indicated as black dashed line. The $95 \%$ confidence limits are highlighted as gray regions.

tation growth stage (Fig. 10 are in agreement with these findings. Conversely, variations in $\sigma_{V H}^{0} / \sigma_{V V}^{0}$ and RVI values are higher than DpRVI, which is likely due to lower attenuation of the co-pol channel at pod development stages.

The correlation plots in Fig. 11 indicate that DpRVI values are better correlated with the biophysical parameters than $\sigma_{V H}^{0} / \sigma_{V V}^{0}$ and RVI. The coefficients of determination $\left(R^{2}\right)$ for PAI, VWC, and DB with DpRVI are 0.58, 0.55, and 0.57, respectively. Even though the correlations are statistically sig- 
nificant, the $R^{2}$ values are lower than that of canola (Fig. 8). This aspect is likely because the vegetation indices derived for low biomass soybean canopy is highly affected by the underlying soil rather than the vegetation canopy.

\subsection{Wheat}

Compared to canola and soybean, wheat belongs to the graminaceous family, which is characterized by erectophile (canopy elements have predominant vertical distribution) architecture. Thus this morphological diversity is characterized by distinctive backscatter responses and associated vegetation indices. In the test site, wheat was sown during the start of May. Most fields were at the tillering stage on 13 June and then advanced to the heading stage by the end of June. Subsequently, flowering, fruit development started during the mid-week of July. The onset of dough and maturity stages began at the end of July. The corresponding vegetation indices derived from time-series Sentinel-1 data are shown in Fig. 12 .

Variations in DpRVI values among three representative fields (Field no. 220, 233, and 62) are evident with vegetation growth. Lowest DpRVI values are observed when wheat advanced from the leaf development to the tillering stage on 13 June. Fields with plant density (PD) of $\approx 100 \mathrm{~m}^{-2}$ (Fields no. 220) have low DpRVI values $(\approx 0.22)$, which are comparatively lower than wheat fields (Field no. 233 and 62) with high PD $\left(125 \mathrm{~m}^{-2}\right.$ and $\left.190 \mathrm{~m}^{-2}\right)$. In-situ measurements of PAI and VWC are also relatively higher $\left(>2.5 \mathrm{~m}^{2} \mathrm{~m}^{-2}\right.$ and $\approx 1.1 \mathrm{~kg} \mathrm{~m}^{-2}$ ) for wheat fields with high plant density. In comparison to other crops, wheat gained more vegetative components on 13 June, which lead to higher DpRVI values. The $m-\beta$ polar plot (Fig. 13) also show moderate to high values of $m(\approx 0.65)$ and $\beta\left(\cos 35^{\circ}=0.82\right)$ on 13 June. 


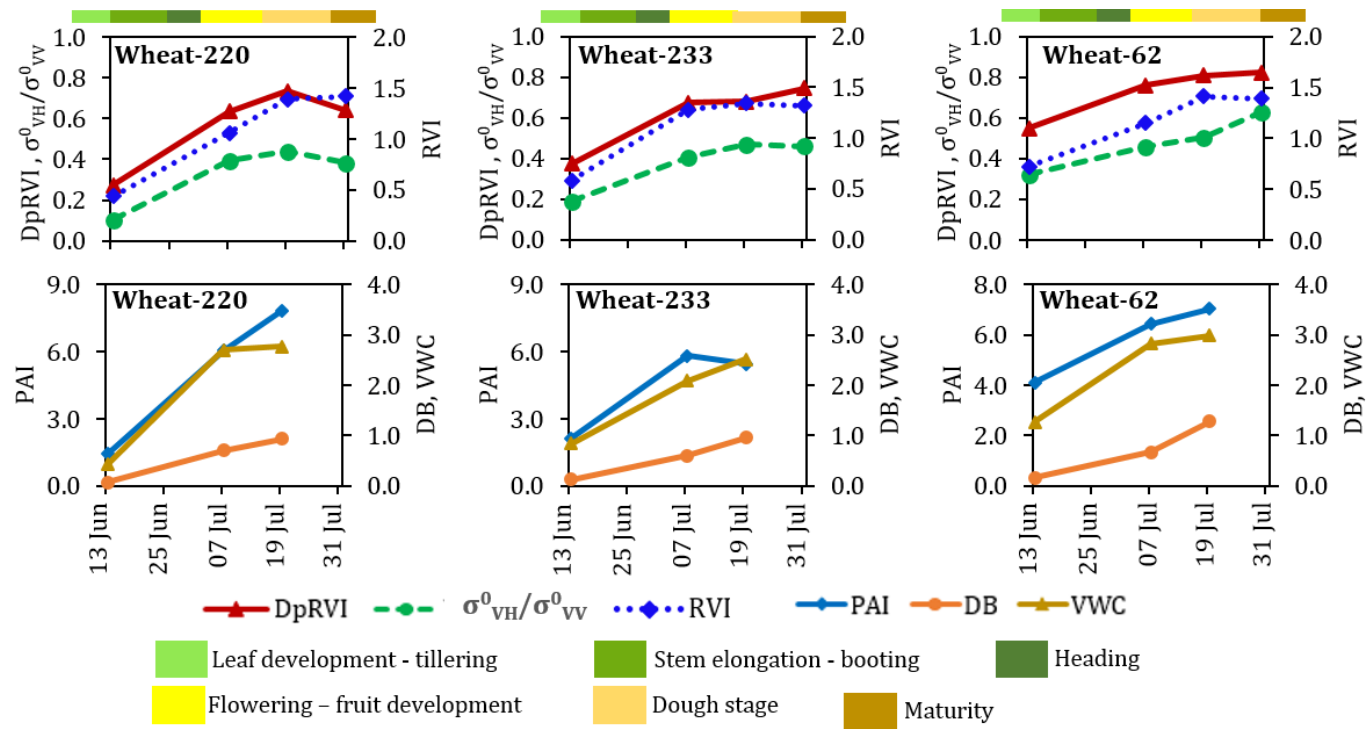

Figure 12: Temporal pattern of vegetation indices (DpRVI, $\sigma_{V H}^{0} / \sigma_{V V}^{0}$ and RVI) for three representative wheat fields at different growth stages. The in-situ measurements of Plant Area Index (PAI, $\mathrm{m}^{2} \mathrm{~m}^{-2}$ ), Vegetation water content (VWC, $\mathrm{kg} \mathrm{m}^{-2}$ ), and dry biomass $\left(\mathrm{DB}, \mathrm{kg} \mathrm{m}^{-2}\right)$ are plotted in second row for each field.

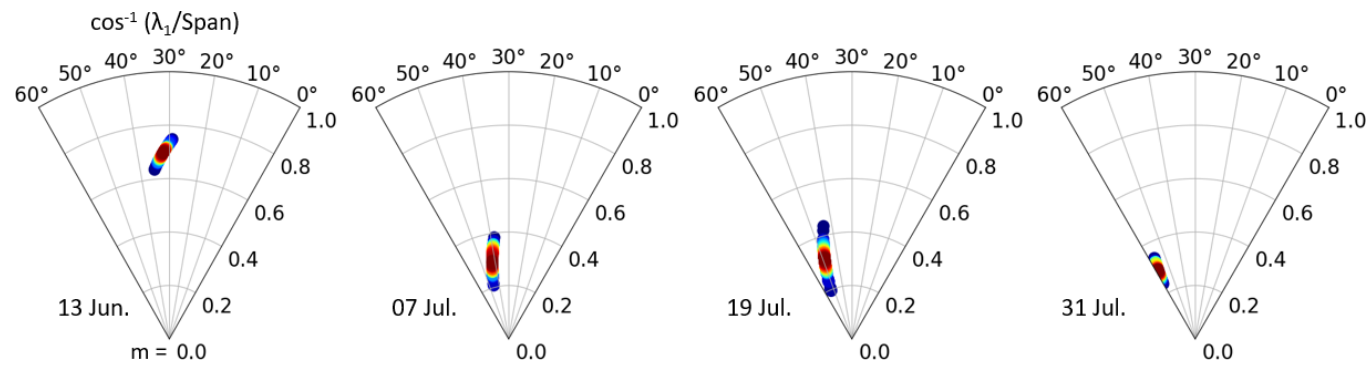

Figure 13: Temporal variations of degree of polarization $(\mathrm{m})$ and $\beta$ in polar plots for wheat fields.

The DpRVI values reached its maximum when the crop advanced from flowering to early dough stages on 19 July. DpRVI reaches up to 0.74 for low PD fields (Field no. 220), while these values peak at $\approx 0.8$ for fields with high PD (Field no. 233 and 62). This difference may be due to the high 

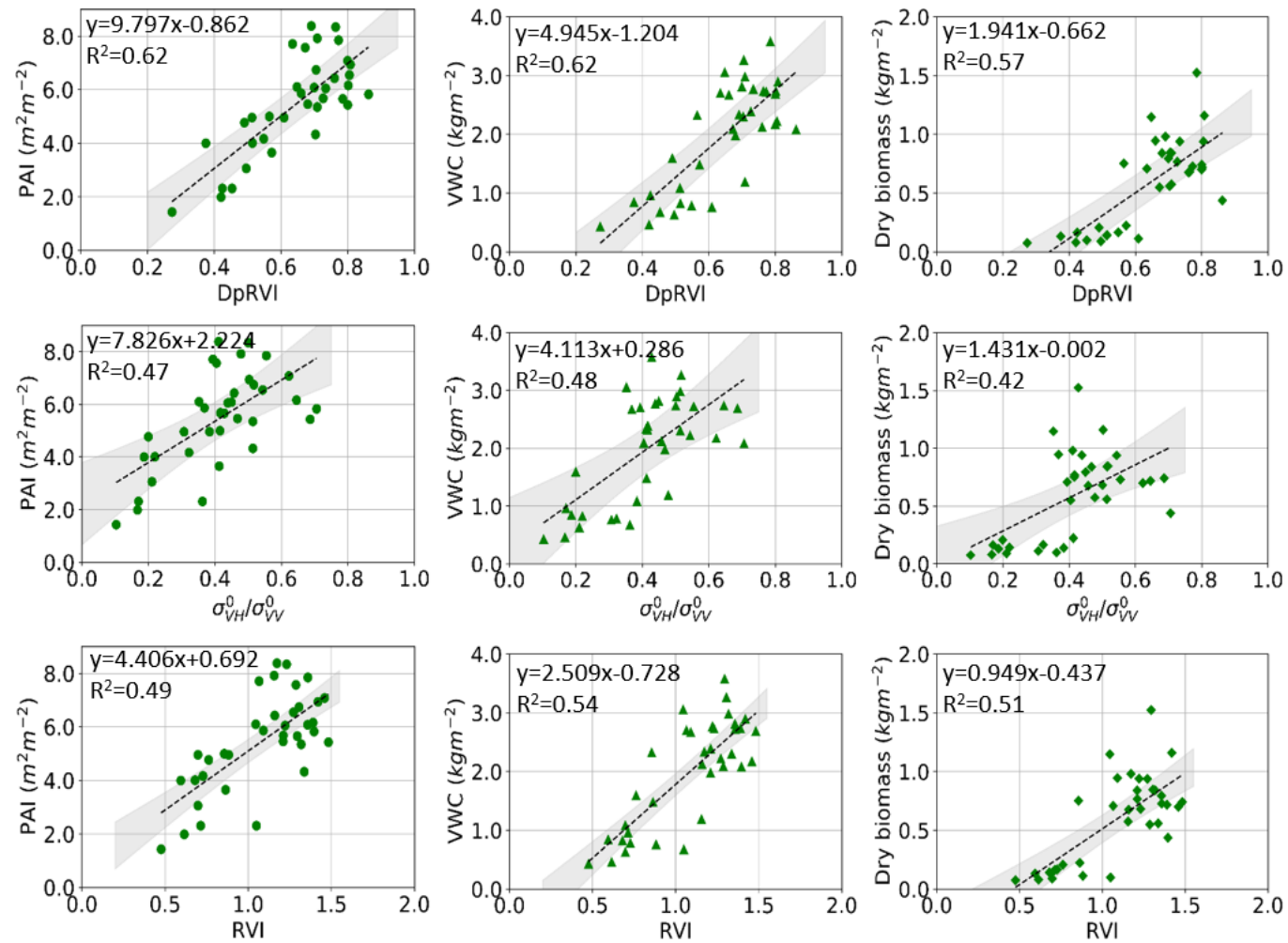

Figure 14: Correlation analysis between vegetation indices (DpRVI, $\sigma_{V H}^{0} / \sigma_{V V}^{0}$ and RVI) and crop biophysical parameters, i.e., Plant Area Index (PAI, $\mathrm{m}^{2} \mathrm{~m}^{-2}$ ), Vegetation water content (VWC, $\mathrm{kg} \mathrm{m}^{-2}$ ), and dry biomass (DB, $\mathrm{kg} \mathrm{m}^{-2}$ ) for wheat. The linear regression line is indicated as black dashed line. The $95 \%$ confidence limits are highlighted as gray regions..

degree of randomness in scattering $\left(m \approx 0.35\right.$ and $\cos ^{-1} \beta \approx 50^{\circ}-55^{\circ}$ on 19 July) from the canopy elements during the flowering to fruit development stages. In-situ measurements of plant biophysical parameters at these stages confirm their increment up to approximately 6.2 to $8.1 \mathrm{~m}^{2} \mathrm{~m}^{-2}, 3.0 \mathrm{~kg} \mathrm{~m}^{-2}$, and $1.1 \mathrm{~kg} \mathrm{~m}^{-2}$, for PAI, VWC, and DB, respectively. This indicates high multiple scattering from the canopy which might lead to $\lambda_{1} \approx \lambda_{2} \approx \mathrm{Span} / 2$ (i.e., no dominant scattering) with low values of $m(\approx 0.25)$. The differential 
increase in DpRVI among the wheat fields is visible in Fig. 12, Variations in plant density might cause a difference in DpRVI values among several fields, even though they are in the identical phenological stage. The rate of increase in DpRVI values slows down at the end of July after the stagnation of vegetative growth and the onset of seed development. Similarly, the values of $\sigma_{V H}^{0} / \sigma_{V V}^{0}$ and RVI follow the vegetation growth trends of wheat. $\sigma_{V H}^{0} / \sigma_{V V}^{0}$ increases during heading to flowering as the plant biomass increases. Similar results are also reported by Veloso et al. (2017) for cereal crops during these phenology stages.

The correlation analysis of vegetation indices with plant biophysical parameters is shown in Fig. 14. The $R^{2}$ of DpRVI with PAI, VWC, and DB are $0.62,0.62$, and 0.57 , respectively, which are higher than the $R^{2}$ of $\sigma_{V H}^{0} / \sigma_{V V}^{0}$ and RVI. The dispersion of DpRVI values in the correlation plot at later growth stages are likely due to scattering from the upper canopy layer (i.e., wheat heads). Wu et al. (1985) reported similar results that the wheat heads dominate the total scattering power at the heading stage with a groundbased scatterometer experiment. However, during the ripening stage (when the heads become drier), the backscatter from the ground becomes dominant, and the backscatter power from the heads is insensitive to the moisture content. Furthermore, variations in backscatter power are less prominent with changes in the leaf area or biomass (Jia et al., 2013).

\section{Conclusion}

We have proposed a dual-pol radar vegetation index (DpRVI) for Sentinel1 (VV-VH) SAR data. The index is derived using the degree of polarization 
$(m)$ and the dominant normalized eigenvalue $\left(\beta=\lambda_{1} /\right.$ Span $)$ obtained from the $2 \times 2$ covariance matrix. The DpRVI is assessed for three crop types (viz., canola, soybean, and wheat) to characterize vegetation growth throughout its phenology. The DpRVI followed the advancement of plant growth until full canopy development with the accumulation of Plant Area Index (PAI) and biomass (vegetation water content (VWC) and dry biomass (DB)), which is evident from its high correlation with these parameters.

Among the results obtained from three different crops, canola indicated the highest correlation $\left(R^{2}\right)$ with its biophysical parameters: 0.79 (PAI), 0.82 (VWC), and 0.75 (DB). In contrast, DpRVI showed moderate correlations with biophysical parameters of wheat and soybean. It is noted that the correlations of DpRVI are comparatively better than that of $\sigma_{V H}^{0} / \sigma_{V V}^{0}$ and dual-pol RVI for all crops. Instead of utilizing the polarization channel backscatter intensities, the DpRVI uses the normalized dominant eigenvalue and the degree of polarization, which are roll and polarization basis invariant. It can be concluded that the DpRVI effectively incorporates both the scattered and received wave information to describe the phenological changes that are vital for time-series crop monitoring.

Notably, the proposed DpRVI for dual-pol SAR data holds significant interest from an operational perspective for the Sentinel-1 Copernicus mission and upcoming SAR missions, e.g., the RADARSAT Constellation Mission (RCM) and NISAR which provide data in larger spatial extent with a short revisit time. For example, end-users might be interested in weekly vegetation condition products from an operational mission like the Sentinel-1. In fact, the frequent revisit of SAR satellites is necessary to monitor critical 
phenological stages during the crop season. With the synergy of Sentinel-1A and $1 \mathrm{~B}$, monitoring crop conditions over national scales with dual-pol indices would be an adequate proxy. However, implications with the HH-HV mode is required to be further examined as crop response could be different for horizontally polarized transmitted wave than the vertical. Moreover, experimental validation of vegetation indices on the incidence angle variations is necessary for wide swath products. The vegetation index needs to be further investigated for different cropping systems at various test sites for validation with dense time-series data cube under the JECAM SAR Inter-Comparison Experiment at an operational scale.

\section{Appendix A. Relationship between $m$ and $\beta$}

The eigen-decomposition of a $2 \times 2$ covariance matrix, $\mathbf{C}_{2}$ can be expressed as,

$$
\mathbf{C}_{2}=\mathbf{U}_{2} \Sigma \mathbf{U}_{2}^{-1}
$$

where,

$$
\boldsymbol{\Sigma}=\left[\begin{array}{ll}
\lambda_{1} & 0 \\
0 & \lambda_{2}
\end{array}\right]
$$

504 is a $2 \times 2$ diagonal matrix with nonnegetive elements, $\lambda_{1} \geq \lambda_{2} \geq 0$, which are the eigenvalues of the covariance matrix, and $\mathbf{U}_{2}$ is a $2 \times 2$ unitary matrix whose columns are the eigenvectors of the covariance matrix.

The degree of polarization $(m)$ of the EM wave is derived from the ex- 
pression given by Barakat (1977) as,

$$
m=\sqrt{1-\frac{4\left|\mathbf{C}_{2}\right|}{\left(\operatorname{Tr}\left(\mathbf{C}_{2}\right)\right)^{2}}}
$$

It can be noted that $m$ can also be expressed in terms of the eigenvalues as,

$$
m=\sqrt{\left[1-\frac{4 \lambda_{1} \lambda_{2}}{\left(\lambda_{1}+\lambda_{2}\right)^{2}}\right]}=\sqrt{\left[\frac{\left(\lambda_{1}+\lambda_{2}\right)^{2}-4 \lambda_{1} \lambda_{2}}{\left(\lambda_{1}+\lambda_{2}\right)^{2}}\right]}=\frac{\lambda_{1}-\lambda_{2}}{\lambda_{1}+\lambda_{2}}
$$

The normalized dominant eigenvalue, $\beta$ is given as, $\lambda_{1} /$ Span $=\lambda_{1} /\left(\lambda_{1}+\lambda_{2}\right)$. Hence, the differential variation between $m$ and $\beta$ is expressed as, $\beta-m=$ $\lambda_{2} /\left(\lambda_{1}+\lambda_{2}\right)=\lambda_{2} /$ Span

\section{Disclosures}

No potential conflict of interest is reported by the authors.

\section{Acknowledgment}

The authors would like to thank the ground team members for data collection through the SMAPVEX16-MB campaign, and the European Space Agency (ESA) for providing Sentinel-1 through Copernicus Open Access Hub. Authors acknowledge the GEO-AWS Earth Observation Cloud Credits Program, which supported the computation on AWS cloud platform through the project "AWS4AgriSAR-Crop inventory mapping from SAR data on cloud computing platform". 


\section{References}

Agriculture, M. B., 2016. Agriculture-Province of Manitoba.

URL http://www.gov.mb.ca/agriculture/crops/seasonal-reports/ crop-report-archive/index.html

Ainsworth, T., Kelly, J., Lee, J.-S., 2009. Classification comparisons between dual-pol, compact polarimetric and quad-pol SAR imagery. ISPRS Journal of Photogrammetry and Remote Sensing 64 (5), 464-471.

Barakat, R., 1977. Degree of polarization and the principal idempotents of the coherency matrix. Optics Communications 23 (2), 147-150.

Bargiel, D., 2017. A new method for crop classification combining time series of radar images and crop phenology information. Remote sensing of environment 198, 369-383.

Bhuiyan, H. A., McNairn, H., Powers, J., Friesen, M., Pacheco, A., Jackson, T. J., Cosh, M. H., Colliander, A., Berg, A., Rowlandson, T., et al., 2018. Assessing SMAP soil moisture scaling and retrieval in the Carman (Canada) study site. Vadose Zone Journal 17 (1), doi: 10.2136/vzj2018. 07.0132 .

Blaes, X., Defourny, P., Wegmuller, U., Della Vecchia, A., Guerriero, L., Ferrazzoli, P., 2006. C-band polarimetric indexes for maize monitoring based on a validated radiative transfer model. IEEE transactions on geoscience and remote sensing $44(4), 791-800$.

Bousbih, S., Zribi, M., Lili-Chabaane, Z., Baghdadi, N., El Hajj, M., Gao, Q., 
Mougenot, B., 2017. Potential of Sentinel-1 radar data for the assessment of soil and cereal cover parameters. Sensors 17 (11), 2617.

Cable, J., Kovacs, J., Jiao, X., Shang, J., 2014. Agricultural monitoring in northeastern Ontario, Canada, using multi-temporal polarimetric RADARSAT-2 data. Remote Sensing 6 (3), 2343-2371.

Canisius, F., Shang, J., Liu, J., Huang, X., Ma, B., Jiao, X., Geng, X., Kovacs, J. M., Walters, D., 2018. Tracking crop phenological development using multi-temporal polarimetric Radarsat-2 data. Remote Sensing of Environment 210, 508-518.

Chang, J. G., Shoshany, M., Oh, Y., 2018. Polarimetric radar vegetation index for biomass estimation in desert fringe ecosystems. IEEE Transactions on Geoscience and Remote Sensing 56 (12), 7102-7108.

Denize, J., Hubert-Moy, L., Betbeder, J., Corgne, S., Baudry, J., Pottier, E., 2019. Evaluation of using Sentinel-1 and-2 time-series to identify winter land use in agricultural landscapes. Remote Sensing 11 (1), 37.

ESA, 2015. User Guides - Sentinel-1 SAR.

ESA, 2017. Sen4CAP - Sentinels for Common Agriculture Policy.

URL http://esa-sen4cap.org/

Fehr, W., Caviness, C., Burmood, D., Pennington, J., 1971. Stage of development descriptions for soybeans, Glycine Max (L.) Merrill 1. Crop science 11 (6), 929-931. 
Fikriyah, V. N., Darvishzadeh, R., Laborte, A., Khan, N. I., Nelson, A., 2019. Discriminating transplanted and direct seeded rice using Sentinel-1 intensity data. International Journal of Applied Earth Observation and Geoinformation 76, 143-153.

Gururaj, P., Umesh, P., Shetty, A., 2019. Assessment of spatial variation of soil moisture during maize growth cycle using SAR observations. In: Remote Sensing for Agriculture, Ecosystems, and Hydrology XXI. Vol. 11149. International Society for Optics and Photonics, p. 1114916.

Inglada, J., Vincent, A., Arias, M., Marais-Sicre, C., 2016. Improved early crop type identification by joint use of high temporal resolution SAR and optical image time series. Remote Sensing 8 (5), 362.

Jia, M., Tong, L., Zhang, Y., Chen, Y., 2013. Multitemporal radar backscattering measurement of wheat fields using multifrequency (L, S, C, and X) and full-polarization. Radio Science 48 (5), 471-481.

Khabbazan, S., Vermunt, P., Steele-Dunne, S., Ratering Arntz, L., Marinetti, C., van der Valk, D., Iannini, L., Molijn, R., Westerdijk, K., van der Sande, C., 2019. Crop monitoring using Sentinel-1 data: A case study from The Netherlands. Remote Sensing 11 (16), 1887.

Kim, Y., van Zyl, J. J., 2009. A time-series approach to estimate soil moisture using polarimetric radar data. IEEE Trans. Geosci. Remote Sens. 47 (8), $2519-2527$.

Kumar, P., Prasad, R., Gupta, D., Mishra, V., Vishwakarma, A., Yadav, V., Bala, R., Choudhary, A., Avtar, R., 2018. Estimation of winter wheat 
crop growth parameters using time series Sentinel-1A SAR data. Geocarto international 33 (9), 942-956.

Kussul, N., Lemoine, G., Gallego, F. J., Skakun, S. V., Lavreniuk, M., Shelestov, A. Y., 2016. Parcel-based crop classification in Ukraine using Landsat-8 data and Sentinel-1A data. IEEE Journal of Selected Topics in Applied Earth Observations and Remote Sensing 9 (6), 2500-2508.

Lasko, K., Vadrevu, K. P., Tran, V. T., Justice, C., 2018. Mapping double and single crop paddy rice with Sentinel-1A at varying spatial scales and polarizations in Hanoi, Vietnam. IEEE journal of selected topics in applied earth observations and remote sensing 11 (2), 498-512.

Lee, J.-S., Grunes, M. R., Pottier, E., 2001. Quantitative comparison of classification capability: Fully polarimetric versus dual and single-polarization sar. IEEE Transactions on Geoscience and Remote Sensing 39 (11), 23432351.

Mandal, D., Kumar, V., Bhattacharya, A., Rao, Y., McNairn, H., 2018a. Crop biophysical parameters estimation with a multi-target inversion scheme using the Sentinel-1 SAR data. In: IGARSS 2018-2018 IEEE International Geoscience and Remote Sensing Symposium. IEEE, pp. 66116614 .

Mandal, D., Kumar, V., Bhattacharya, A., Rao, Y. S., Siqueira, P., Bera, S., 2018b. Sen4Rice: A processing chain for differentiating early and late transplanted rice using time-series Sentinel-1 SAR data with Google Earth engine. IEEE Geoscience and Remote Sensing Letters 15 (12), 1947-1951. 
Mandal, D., Kumar, V., Ratha, D., Lopez-Sanchez, J. M., Bhattacharya, A., McNairn, H., Rao, Y., Ramana, K., 2020. Assessment of rice growth conditions in a semi-arid region of India using the Generalized Radar Vegetation Index derived from RADARSAT-2 polarimetric SAR data. Remote Sensing of Environment 237, 111561.

McNairn, H., Champagne, C., Shang, J., Holmstrom, D., Reichert, G., 2009. Integration of optical and Synthetic Aperture Radar (SAR) imagery for delivering operational annual crop inventories. ISPRS Journal of Photogrammetry and Remote Sensing 64 (5), 434-449.

McNairn, H., Jiao, X., Pacheco, A., Sinha, A., Tan, W., Li, Y., 2018. Estimating canola phenology using synthetic aperture radar. Remote sensing of environment 219, 196-205.

McNairn, H., Shang, J., 2016. A review of multitemporal synthetic aperture radar (SAR) for crop monitoring. In: Multitemporal Remote Sensing. Springer, pp. 317-340.

McNairn, H., Tom, J., J., Powers, J., Blair, S., Berg, A., Bullock, P., Colliander, A., Cosh, M. H., Kim, S.-B., Ramata, M., Pacheco, A., Merzouki, A., 2016. Experimental plan SMAP validation experiment 2016 in Manitoba, Canada (SMAPVEX16-MB).

URL https://smap.jpl.nasa.gov/internal_resources/390/

Nasirzadehdizaji, R., Balik Sanli, F., Abdikan, S., Cakir, Z., Sekertekin, A., Ustuner, M., 2019. Sensitivity Analysis of Multi-Temporal Sentinel-1 SAR 
Parameters to Crop Height and Canopy Coverage. Applied Sciences 9 (4), 655.

Nelson, A., Setiyono, T., Rala, A., Quicho, E., Raviz, J., Abonete, P., Maunahan, A., Garcia, C., Bhatti, H., Villano, L., et al., 2014. Towards an operational SAR-based rice monitoring system in Asia: Examples from 13 demonstration sites across Asia in the RIICE project. Remote Sensing 6 (11), 10773-10812.

Nguyen, D. B., Gruber, A., Wagner, W., 2016. Mapping rice extent and cropping scheme in the Mekong Delta using Sentinel-1A data. Remote Sensing Letters 7 (12), 1209-1218.

Pacheco, A., McNairn, H., Li, Y., Lampropoulos, G., Powers, J., 2016. Using RADARSAT-2 and TerraSAR-X satellite data for the identification of canola crop phenology. In: Remote Sensing for Agriculture, Ecosystems, and Hydrology XVIII. Vol. 9998. International Society for Optics and Photonics, p. 999802.

Periasamy, S., 2018. Significance of dual polarimetric synthetic aperture radar in biomass retrieval: An attempt on Sentinel-1. Remote sensing of environment 217, 537-549.

Shirvany, R., Chabert, M., Tourneret, J.-Y., 2012. Estimation of the degree of polarization for hybrid/compact and linear dual-pol SAR intensity images: Principles and applications. IEEE Transactions on Geoscience and Remote Sensing 51 (1), 539-551. 
Singha, M., Dong, J., Zhang, G., Xiao, X., 2019. High resolution paddy rice maps in cloud-prone Bangladesh and Northeast India using Sentinel-1 data. Scientific data 6 (1), 26.

Steele-Dunne, S. C., McNairn, H., Monsivais-Huertero, A., Judge, J., Liu, P., Papathanassiou, K., 2017. Radar remote sensing of agricultural canopies: A review. IEEE Journal of Selected Topics in Applied Earth Observations and Remote Sensing 10 (5), 2249-2273.

Touzi, R., Hurley, J., Vachon, P. W., 2015. Optimization of the degree of polarization for enhanced ship detection using polarimetric RADARSAT-2. IEEE Transactions on Geoscience and Remote Sensing 53 (10), 5403-5424.

Touzi, R., Omari, K., Sleep, B., Jiao, X., 2018. Scattered and received wave polarization optimization for enhanced peatland classification and fire damage assessment using polarimetric PALSAR. IEEE Journal of Selected Topics in Applied Earth Observations and Remote Sensing 11 (11), 4452-4477.

Trudel, M., Charbonneau, F., Leconte, R., 2012. Using RADARSAT-2 polarimetric and ENVISAT-ASAR dual-polarization data for estimating soil moisture over agricultural fields. Canadian Journal of Remote Sensing $38(4), 514-527$.

Van Tricht, K., Gobin, A., Gilliams, S., Piccard, I., 2018. Synergistic use of radar Sentinel-1 and optical Sentinel-2 imagery for crop mapping: A case study for Belgium. Remote Sensing 10 (10), 1642. 
Veloso, A., Mermoz, S., Bouvet, A., Le Toan, T., Planells, M., Dejoux, J.F., Ceschia, E., 2017. Understanding the temporal behavior of crops using Sentinel-1 and Sentinel-2-like data for agricultural applications. Remote Sensing of Environment 199, 415-426.

Vreugdenhil, M., Wagner, W., Bauer-Marschallinger, B., Pfeil, I., Teubner, I., Rüdiger, C., Strauss, P., 2018. Sensitivity of Sentinel-1 backscatter to vegetation dynamics: An Austrian case study. Remote Sensing 10 (9), 1396.

Wang, H., Magagi, R., Goita, K., 2016. Polarimetric decomposition for monitoring crop growth status. IEEE Geoscience and Remote Sensing Letters $13(6), 870-874$.

Whelen, T., Siqueira, P., 2018. Time-series classification of Sentinel-1 agricultural data over North Dakota. Remote sensing letters 9 (5), 411-420.

Wigneron, J.-P., Pardé, M., Waldteufel, P., Chanzy, A., Kerr, Y., Schmidl, S., Skou, N., 2004. Characterizing the dependence of vegetation model parameters on crop structure, incidence angle, and polarization at L-band. IEEE Transactions on Geoscience and Remote Sensing 42 (2), 416-425.

Wiseman, G., McNairn, H., Homayouni, S., Shang, J., 2014. RADARSAT2 polarimetric SAR response to crop biomass for agricultural production monitoring. IEEE Journal of Selected Topics in Applied Earth Observations and Remote Sensing 7 (11), 4461-4471.

Wu, L.-k., Moore, R. K., Zoughi, R., 1985. Sources of scattering from vege- 
${ }_{699}$ tation canopies at $10 \mathrm{GHz}$. IEEE Trans. Geosci. Remote Sens. GE-23 (5), 737-745. 